Aurelia Journal
(Authentic Research of Global Fisheries Application Journal)
p-ISSN: 0000-0000
e-mail: aurelia.journal@gmail.com

\title{
PERAWATAN FRESH WATER COOLER PADA SISTEM PENDINGINAN MESIN DIESEL PENGGERAK GENERATOR LISTRIK DI KAPAL NAVIGASI MILIK DISTRIK NAVIGASI KELAS I AMBON
}

\section{MAINTENANCE OF FRESHWATER COOLER IN THE COOLING SYSTEM OF DIESEL ENGINE AS A ELECTRIC GENERATOR DRIVER IN NAVIGATION SHIP OF AMBON CLASS I NAVIGATION}

\author{
Demianus W. Sroyer ${ }^{*}$, M. Zaki Latif Abrori', Sigit D.P Sidhi1 \\ 1Politeknik Kelautan dan Perikanan Sorong \\ *Korespondensi: sroyer.dw@gmail.com (DW Sroyer) \\ Diterima 5 Juli 2019 - Disetujui 10 September 2019
}

\begin{abstract}
ABSTRAK. Mesin diesel merupakan mesin yang paling banyak digunakan sebagai sumber energi mekanis diatas kapal. Mesin diesel adalah salah satu mesin pembakaran dalam yang menghasilkan energi gerak dan energi panas. Panas berlebihan pada mesin mengakibatkan kerusakan mesin. Untuk mencegah panas yang berlebihan pada mesin diesel maka diperlukan pendinginan yang tepat, salah satu komponen yang bertugas sebagai pendingin mesin adalah fresh water cooler (FWC) berupa heat exchager. Gagalnya FWC untuk mendinginkan air tawar sebagai media pendingin mesin mengakibatkan kerusakan mesin. Perawatan FWC merupakan tindakan untuk mengembalikan kemampuan FWC pada kondisi yang prima untuk mendinginkan fresh water dan mencegah terjadinya kegagalan mesin akibat temperatur mesin yang melebihi batas yang ditentukan. Adapun tujuan penelitian ini adalah untuk mengetahui bagaimana tindakan perawatan yang dilakukan pada FWC sistem pendinginan mesin diesel penggerak generator listrik menggunakan metode studi kasus yang pada kapal navigasi, hasil penelitian dipaparkan secara diskriptif. Kesimpulan penelitian ini perawatan FWC pada kapal navigasi sudah berjalan dengan baik, dilaksanakan sesuai instruksi kerja petunjuk mesin, sesuai jadwal, hasil perawatan didapat temperatur mesin kembali sesuai dengan yang diharapkan.
\end{abstract}

KATA KUNCI: Perawatan; fresh water cooler, pendingin mesin

ABSTRACT. The diesel engine is the most widely used engine as a mechanical energy source on board. A diesel engine is one of the internal combustion engines that produce motion energy and heat energy. Excessive heat the engine results in engine damage. To prevent overheating of the diesel engine, proper cooling is needed, one of the components that serve as engine coolant is the fresh water cooler (FWC) in the form of a heat exchanger. The failure of FWC to cool fresh water as an engine cooling medium resulted in engine damage. FWC maintenance is an action to restore FWC's ability to prime conditions to cool fresh water and prevent engine failure due to engine temperatures exceeding the specified limit. The purpose of this research is to find out how the treatment actions carried out on the FWC cooling system of the electric generator driving the diesel engine use a case study method that on navigation vessels, the results of the study are presented descriptively. The conclusion of this research is that FWC maintenance on navigation vessels has been running well, carried out according to the instructions of the machine work instructions, according to the schedule, the results of treatment obtained the engine temperature returned as expected.

KEYWORDS: Maintenance; fresh water cooler; engine coolant 


\section{Pendahuluan}

Pilihan menggunakan mesin penggerak di atas kapal lebih banyak pada mesin diesel daripada mesin jenis lain, hal ini karena dengan ukuran yang sama mesin diesel memiliki daya (horse power) yang cukup besar (Pujo \& Akhmad, 2010). Mesin diesel juga banyak di pilih sebagai mesin penggerak karena tahan dan efektif untuk di operasikan dalam waktu yang cukup lama (Abrori, Priharanto, Prasetyo \& Muhfizar, 2018).

Perawatan mesin di atas kapal sangat penting dan tidak dapat di hindari (Priharanto, Latif, \& HS, 2017), karena apabila mesin mengalami kegagalan saat kapal berlayar, mengakibatkan kapal tidak terkontrol dan mengakibatkan dampak yang fatal (Saputra, Priharanto, \& Latif A, 2018). Mesin diesel merupakan mesin yang kompleks, berdasarkan hierarkinya mesin ini terdiri dari sistem, sub-sistem dan komponen. Kemungkinan kegagalan mesin diesel terjadi karena berbagai sebab, seperti sistem bahan bakar, sistem pendingin, sistem pelumas.

Sistem pendingin merupakan sistem yang berfungsi menjaga temperatur mesin pada suhu tertentu sesuai dengan desain yang ditentukan agar mesin diesel dapat beroperasi secara berkelanjutan. Mesin Diesel yang beroperasi menghasilkan panas dengan suhu Sistem pendingin ini terdiri dari beberapa komponen penyusun yang utamanya untuk mendinginkan blok mesin, selain mendinginkan blok mesin, sistem pendingin juga mendinginkan pelumas, scavange air dan water jacket (Julianto, 2019).

Sistem pendingin mesin diesel di atas kapal menggunakan sistem pendinginan tidak langsung. Sistem pendingin tidak langsung ini merupakan sistem pendingin mesin yang menggunakan fresh water yang berikan additive sebagai media untuk mendinginkan mesin, kemudian fresh water ini di dinginkan oleh air laut. Sistem pendingin tidak langsung dipilih karena mesin tidak didinginkan secara langsung oleh air laut sehingga mesin relatif tahan terhadap korosi yang disebabkan oleh air laut. Komponen yang berfungsi mendinginkan air tawar ini umumnya disebut sebagai heat exchanger fresh water cooler.

Pendinginan mesin terjadi ketika mesin sedang beroperasi, operasional mesin diesel dari pembakaran bahan menghasilkan panas dengan suhu lebih dari $200^{\circ} \mathrm{C}$. Kemudian mesin didinginkan oleh fresh water melalui water jacket dengan suhu antara $30-32^{\circ} \mathrm{C}$. Setelah mendinginkan mesin, temperatur fresh water menjadi $93^{\circ} \mathrm{C}$ dan masuk ke dalam FWC untuk di dinginkan dengan air laut dengan temperatur $25-33^{\circ} \mathrm{C}$. Setelah didinginkan oleh air laut temperatur fresh water secara umum menjadi $71^{\circ} \mathrm{C}$ hingga $85^{\circ} \mathrm{C}$ (Zhang et al., 2017) untuk kembali mendinginkan mesin.

Gagalnya FWC untuk mendinginkan mesin akan berdampak pada tingginya temperatur kerja mesin (Faisyal, Aviva, \& Mustafa, 2017) dan ini memiliki pengaruh terhadap kinerja mesin (Soebiyakto, 2012). Tingginya temperatur pada batas yang tidak direkomendasikan dan apabila tidak dilakukan tindakan perbaikan maka implikasinya kegagalan mesin dengan tingkat yang lebih parah. Perawatan FWC merupakan tindakan untuk mengembalikan kemampuan FWC pada kondisi yang prima untuk mendinginkan fresh water, mencegah terjadinya kegagalan mesin akibat temperatur mesin yang melebihi batas yang ditentukan saat mesin sedang beroperasi, oleh karena itu penulis mengambil judul "perawatan fresh water cooler pada sistem pendinginan mesin diesel penggerak generator listrik di kapal navigasi milik Distrik Navigasi Kelas I Ambon yang bertujuan untuk mengetahui bagaimana perawatan yang dilakukan pada FWC sistem pendinginan mesin diesel penggerak generator listrik.

\section{Bahan dan Metode}

Dalam melakukan penulisan artikel perawatan FWC pada sistem pendinginan mesin diesel di lakukan dengan metode studi kasus di Kapal Navigasi milik distrik navigasi yang dipaparkan secara diskriptif. Adapun dalam penelitian ini dilaksanakan dengan beberapa tahapan seperti di tunjukan pada Gambar 1 flow chart penulisan. 


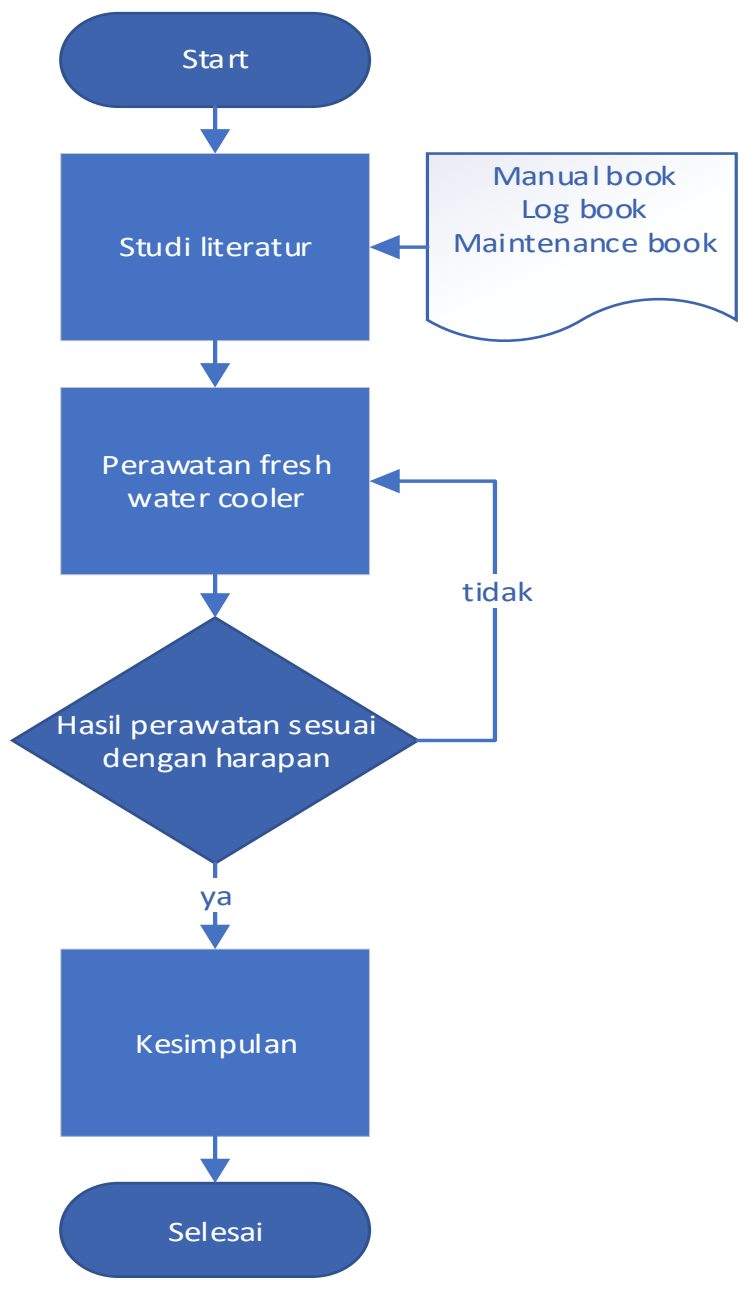

Gambar 1. Flow Chart Penulisan

1. Untuk melakukan penyusunan artikel ini pertama hal yang dilakukan adalah studi literatur mengenai;

a. Mesin diesel yang digunakan diatas kapal melalui general arrangement kapal dan manual book mesin. General arrangment menurut (Basri \& Aryawan, 2019) digunakan untuk menunjukkan dimana lokasi mesin diesel berada. Selanjutnya dengan manual book akan mengetahui sistem dan sub-sistem mesin blok diagram mesin, komponen FWC, spesifikasi teknis dan tipe yang digunakan.

b. Jadwal perawatan mesin. Dengan di lakukannya perawatan mesin sesuai dengan jadwal yang telah direncanakan dapat meminimalkan downtime dan meningkatkan produktivitas mesin (Djunaidi \& Mila Faila Sufa, 2007).

c. Instruksi kerja. Instruksi kerja perlu di perhatikan nantinya untuk diterapkan saat melakukan perawatan FWC. Instruksi kerja ini merupakan prosedur untuk melakukan pekerjaan yang terstruktur untuk memudahkan dalam pekerjaan agar pekerjaan sesuai dengan yang diharapkan dan terhindar dari bahaya mekanis, bahaya fisik dan biaya yang tidak terduga (Aisyah, 2016).

d. MAINTENANCE BOOK digunakan untuk dokumentasi histori perawatan FWC untuk dijadikan sebagai bahan kajian perawatan mesin berikutnya. dalam buku maintenance book ini kemudian dicatat tindakan perawatan yang telah dilakukan.

2. Tindakan perawatan FWC

Merupakan tindakan yang akan dilakukan dalam melakukan perawatan FWC diatas kapal, bilamana dilakukan tindakan perawatan, bagaimana perawatan yang dilakukan apakah sesuai dengan instruksi kerja. 
3. Hasil perawatan

Merupakan hasil dari tindakan perawatan yang telah dilakukan. Apakah hasil perawatan yang telah dilakukan sesuai dengan harapan atau tidak. kalau tidak sesuai maka perawatan tidak tepat dan di ulangi pada tahapan sebelumnya. Bila sesuai maka selanjutnya dapat di tarik kesimpulan.

4. Kesimpulan

Tahap akhir dari artikel ini adalah mengambil kesimpulan untuk menjawab tujuan yang diharapkan pada studi ini yang meliputi bagaimana perawatan yang dilakukan pada FWC sistem pendinginan mesin diesel di kapal navigasi.

\section{Hasil dan Pembahasan}

\subsection{Kapal Navigasi}

Kapal Navigasi merupakan kapal milik kementerian perhubungan yang bertugas untuk melayani kebutuhan rambu sebagai sarana bantu keselamatan pelayaran di perairan Indonesia, mulai dari memasang dan memperbaiki rambu suar hingga untuk mengangkut petugas menara suar dan kebutuhan logistiknya. Amalina \& Kristianto, (2017) dalam publikasinya mengatakan kapal navigasi memiliki tugas untuk kepentingan keselamatan pelayaran melalui pemantauan alur dan perlintasan, perencanaan, pengadaan pengoperasian dan pengawasan sarana bantu navigasi laut hingga survei hidrografi.

\subsection{Mesin Penggerak Generator Kapal Navigasi}

Kapal navigasi ini memiliki dua buah mesin generator listrik dengan spesifikasi yang sama. Mesin generator listrik ini menggunakan mesin diesel sebagai tenaga penggeraknya. Adapun spesifikasi mesin penggeraknya ditampilkan pada Tabel 1.

\section{Tabel 1. Spesifikasi Mesin}

\begin{tabular}{llc}
\multicolumn{1}{c}{ Spesifikasi Teknis } & Keterangan \\
\hline Merek & $:$ & Caterpillar \\
Tipe & $:$ & $3408 \mathrm{C}-\mathrm{TA}$ \\
Daya & $:$ & $229 \mathrm{HP}$ \\
Putaran mesin & $1500 \mathrm{rpm}$ \\
Jumlah silinder & $:$ & 6 \\
Sistem pendingin & $:$ & Tidak langsung \\
Tahun di buat & $:$ & 2008 \\
\hline
\end{tabular}

Adapun obyek penelitian studi kasus sistem pendingin mesin diesel pada komponen penukar panas yaitu heat exchanger yang berupa fresh water cooler dengan spesifikasi ditampilkan pada Tabel 2.

Tabel 2. Spesifikasi Fresh Water Cooler

\begin{tabular}{lc} 
& Spesifikasi Teknis \\
\hline Merek & $:$ Caterpillar \\
Type & $:$ Shell and tube \\
Panjang tube & $: 50 \mathrm{~cm}$ \\
Jumlah tube & $: 212$ tube \\
Diameter (luas- permukaan) & $: 9 \mathrm{~mm}$ \\
Shell material & $:$ Steel \\
Tube material & $: 90 / 10$ CuNi \\
Jenis media - pendingin & $:$ Coolant Inhibitor Caterpillar 217-0616 \\
\hline
\end{tabular}




\subsection{Jadwal Perawatan FWC}

Berdasarkan hasil observasi di kapal navigasi, pelaksanaan perawatan FWC berupa pemeriksaan volume air pendingin (coolant), pemeriksaan dilakukan dengan melihat sight glass pada sisi samping FWC, biasanya coolant perlu di tambah setelah tiga atau empat hari operasi mesin atau 72-96 jam operasi. Perawatan lain pada FWC adalah membersihkan shell and tube FWC setiap 12 hari atau 288 jam operasi. Hal ini sesuai dengan buku manual mesin Caterpillar Inc, (2007) bahwa perawatan harian berupa pemeriksaan coolant level, dan perawatan setiap 250 jam adalah pemeriksaan sampel coolant. Untuk Interval perawatan pembersihan penukar panas shell and tube tergantung pada lingkungan operasi kapal dan waktu operasi kapal.

\subsection{Penambahan Coolant}

Penambahan coolant ke dalam tangki penampung heat exchanger (Gambar 1) dilakukan sebelum mesin di operasikan atau mesin dalam kondisi berhenti, tetapi tidak menutup kemungkinan penambahan saat mesin sedang beroperasi. Hal ini karena instruksi kerja untuk mengoperasikan mesin salah satunya memeriksa volume air pendingin, apabila jumlahnya di setengah dari sight glass maka harus di tambah dengan air pendingin hingga batas atas sight glass.

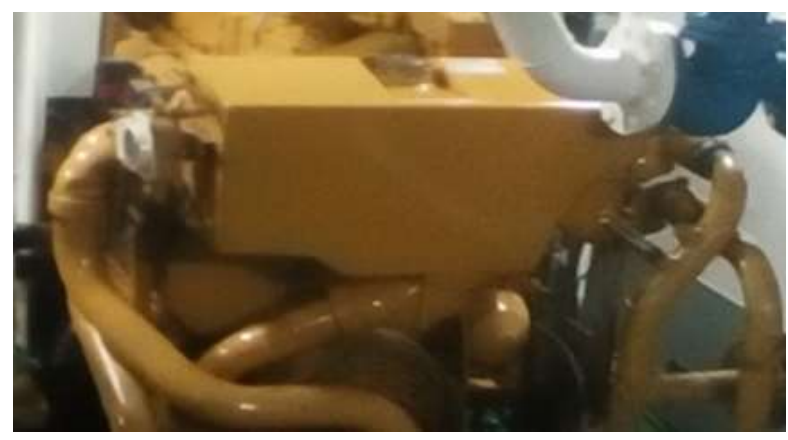

Gambar 1. Fresh Water Cooler

Alat yang digunakan untuk menambah air pendingin yaitu gen kapasitas 35 liter dan corong air. Sementara bahan yang digunakan adalah air tawar dan coolant. Proses membuat larutan pendingin yaitu dengan mencampur coolant sebanyak $500 \mathrm{ml}$ (atau setengah dari pada botol coolant) dengan 30 liter air tawar ke dalam gen kemudian aduk hingga merata.

Untuk menambahkan larutan pendingin mesin dengan cara membuka penutup tangki FWC dan masukan ujung corong ke dalam mulut FWC agar tidak terjadi tumpahan atau percikan air ke body mesin, lalu tuangkan air pendingin ke dalam bak FWC hingga penuh (biasanya \pm 5 liter) dengan indikasi coolant yang memenuhi bak FWC. Tutup kembali mulut bak FWC dengan menggunakan penutupnya. Setelah penambahan ini biasanya FWC ditambah lagi air pendinginnya dalam tiga atau empat hari kemudian (72-96 jam).

\subsection{Cleaning Shell and Tube FWC}

Perawatan yang di lakukan pada bagian FWC adalah membersihkan shell and tube dengan cara di cuci, adapun pelaksanaannya adalah sebagai berikut: pertama siapkan alat dan bahan yang digunakan untuk proses pencucian shell and tube, alat tersebut adalah kunci ring-pas 13,15,19 dan 22, kunci sok 19 dan 22, obeng min (-), corong air, palu, kuas, sikat nilon, pompa air tekanan tinggi dan kompresor udara. Sementara bahan yang disiapkan adalah majun, solar, ember, air tawar, detergen, dan Coolant Inhibitor Caterpillar 217-0616. Untuk tahapannya adalah sebagai berikut:

a. Melepas tube dari shell FWC

Pekerjaan ini di mulai membuang coolant dari dalam FWC melalui jalur drain dengan membuka baut drain, setelah coolant pada FWC habis di drain maka selanjutnya melepas semua baut yang di pasang pada penutup shell FWC (sisi kanan dan kiri) menggunakan kunci ring-pas yang sesuai dengan 
kepala bautnya; membuka paking aluminium yang ada di dinding penutup shell menggunakan obeng min (-); keluarkan tube dengan cara mendorong dari sebelah sisi lainnya menggunakan alas kayu dan pukul kayu dengan palu secara perlahan-lahan; menarik tube secara perlahan-lahan hingga tube keluar dari shell FWC.

b. Cleaning bagian luar tube

Pencucian tube (Gambar 3) dilakukan dengan mencelupkan tube ke dalam ember yang berisi air tawar yang sudah dicampur dengan detergen, karena tube menggunakan material 90/10 CuNi maka dilarang menggunakan pembersih yang mengandung kaustik konsentrat tinggi (Caterpillar Inc, 2010).

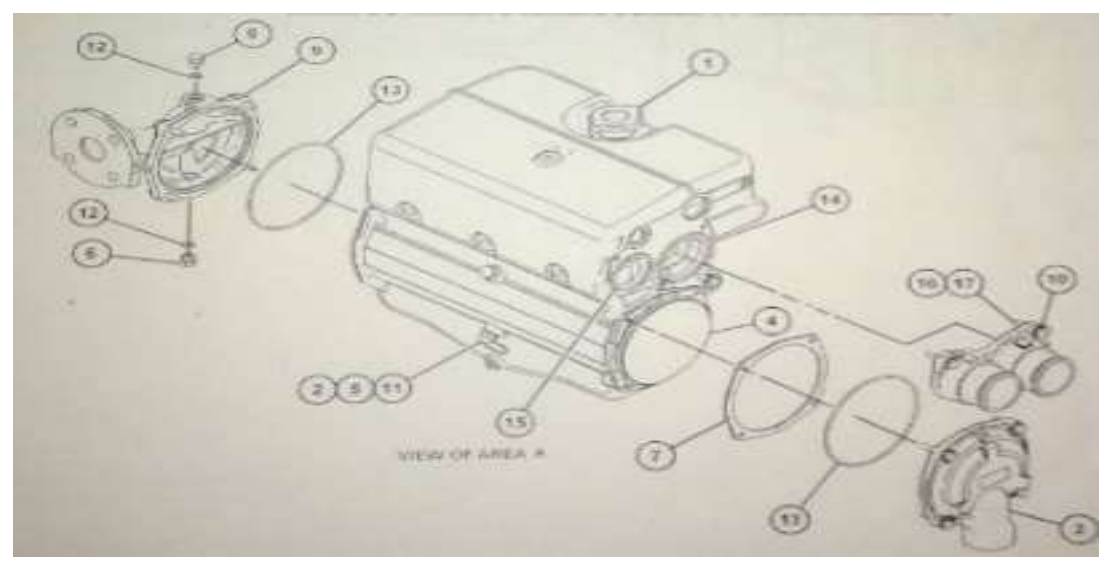

(Sumber: Caterpillar inc 2010)

Gambar 2. Bagian Komponen Fresh Water Cooler

Untuk melepas endapan kotoran yang melekat pada tube gosok kotoran menggunakan majun yang di basahi dengan air detergen, gosok body tube hingga kotoran yang menempel terlepas dan bersih dari kotoran.

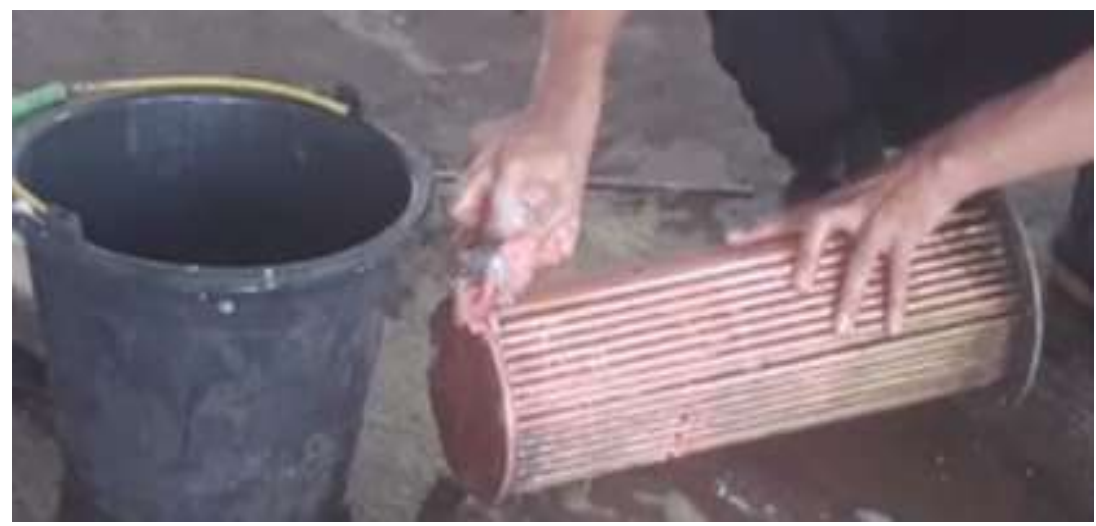

\section{Gambar 3. Pencucian Body Tube Cooler Menggunakan Majun dan Larutan Detergen}

Pada tube yang kotor kadang terdapat kotoran yang tidak dapat dibersihkan dengan majun, untuk kotoran yang sulit dibersihkan dapat di gosok menggunakan sikat nilon. Gambar di atas merupakan tindakan membersihkan tube dengan menggunakan sikat berbulu halus (nilon), sesuai buku panduan Caterpillar Inc, (2010) jika menggunakan sikat kawat kasar maka tube akan tergores lecet dan lambat laun akan mengakibatkan kerusakan.

Menyikat tube dengan cara yang teliti dan tidak tergesa- gesa. Bersihkan tube mulai dari satu sisi ke sisi yang lain sampai masuk di tiap celah-celah sisi tube (Gambar). Ketika membalikkan badan tube saat membersihkan tube haruslah berhati-hati, karena jika badan tube terbentur akan menyebabkan tube penyok dan berdampak tube tidak dapat di masukan kembali ke dalam body dan shell FWC (Faisyal et al., 2017). 


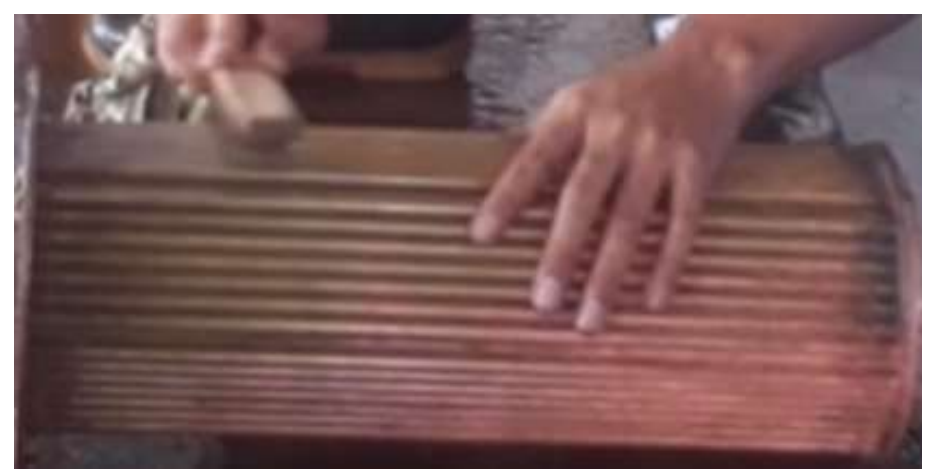

Gambar 5. Membersihkan Tube menggunakan Sikat Nilon

c. Membersihkan bagian dalam tube

Kotoran yang mengendap di dalam tube dapat dibersihkan dengan sikat pembersih khusus tube. Sikat ini menggunakan bahan nilon dengan diameter sikat sesuai ukuran tube yakni 9mm (Gambar 4).

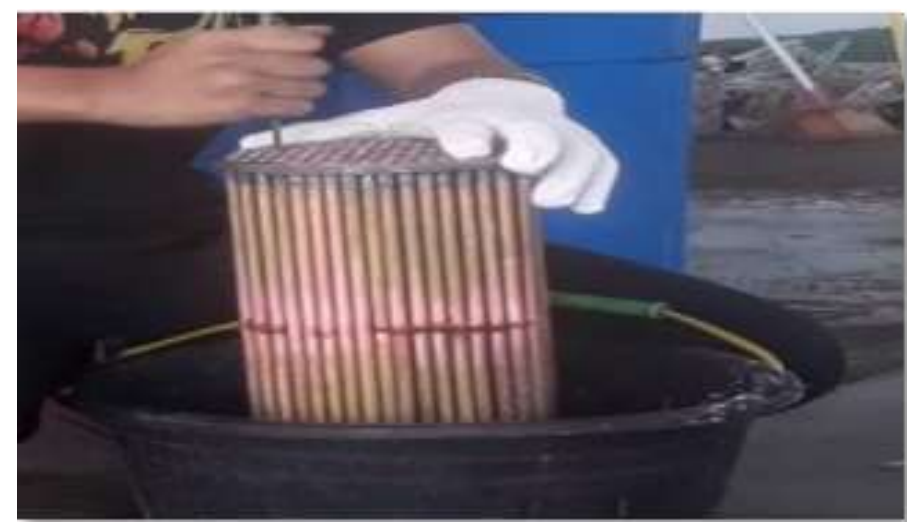

Gambar 4. Pembersihan bagian dalam Tube

Adapun cara membersihkannya dengan cara masukan cooler ke dalam ember yang bersisi air tawar yang sudah tercampur dengan detergen, bersihkan bagian permukaan dinding atas dan bawah, bersihkan bagian dalam tube menggunakan sikat pembersih lubang tube dengan cara menggosok ke dalam tiap-tiap tube secara berurutan untuk mencegah terlewatnya tube dibersihkan. Selanjutnya flush tube (semprot) dengan air tawar bertekanan tinggi, hal ini bertujuan untuk mendorong kotoran sisa yang terperangkap pada dinding tube untuk keluar dari tube. Adapun membersihkannya dengan cara menempelkan nozzle air bertekanan ke dalam salah satu sisi mulut tube dan tarik tuas nozzle untuk menyemprotkan air bertekanan hingga kotoran yang ada di dalam tube ikut keluar terbawa air bertekanan (Gambar 5).

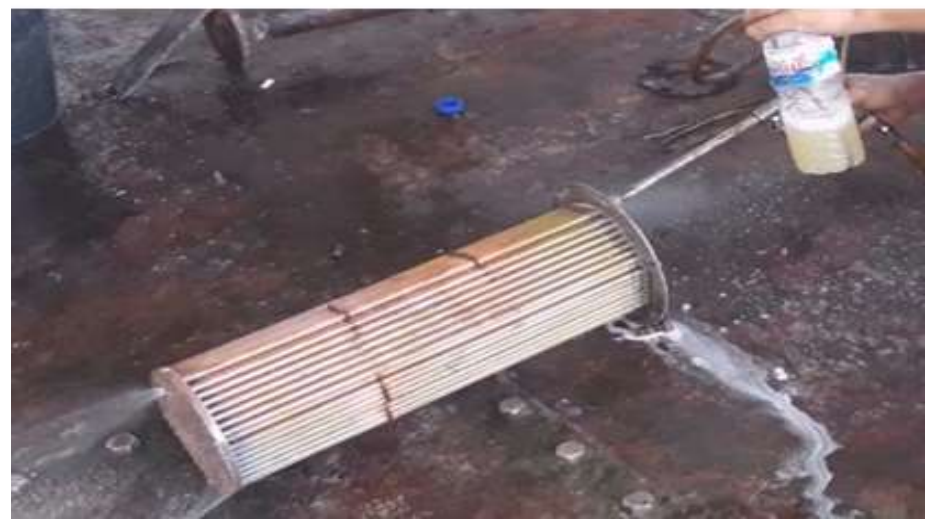

Gambar 5. Flushing Tube menggunakan Air Bertekanan 
Setelah di cuci untuk membersihkan dari sisa air pencucian, semprot cooler menggunakan udara bertekanan dari kompresor udara. Penyemprotan mulai dari sisi body tube sampai dengan bagian dalam tube, kemudian cooler di keringkan dengan cara di tegakkan agar sisa-sisa air yang ada di dalam tube dapat mengalir keluar tube (Gambar 6).

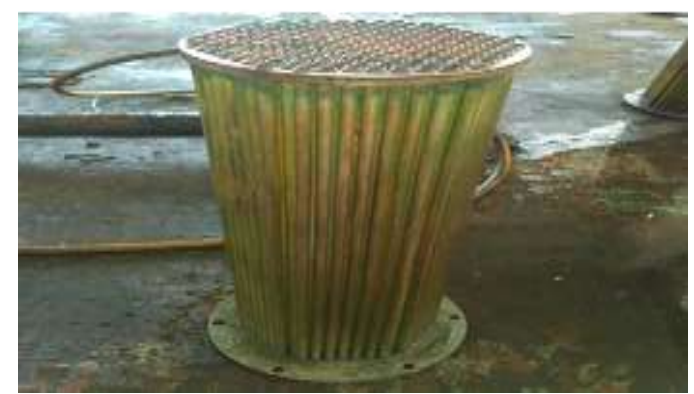

\section{Gambar 6. Keringkan Tube Cooler Sudah Bersih}

d. Membersihkan shell FWC

Untuk memastikan FWC menjadi bersih maka seluruh bodi FWC harus dibersihkan, termasuk bodi dalam dan body luar FWC. Karena bagian luar sering terkena kotoran minyak dan debu, maka untuk membersihkan bagian luar body menggunakan minyak solar dan kuas (Gambar 7).

Proses membersihkan cover FWC sisi luar dengan cara siapkan solar pada wadah kemudian bersihkan cover/penutup FWC menggunakan kuas yang dibasahi dengan solar dan dilanjutkan dengan bilas menggunakan air sabun agar nantinya sisa-sisa solar yang ada pada cover dan tidak ikut terbawa ke dalam media pendinginan dan terakhir dilap dengan menggunakan majun bersih.

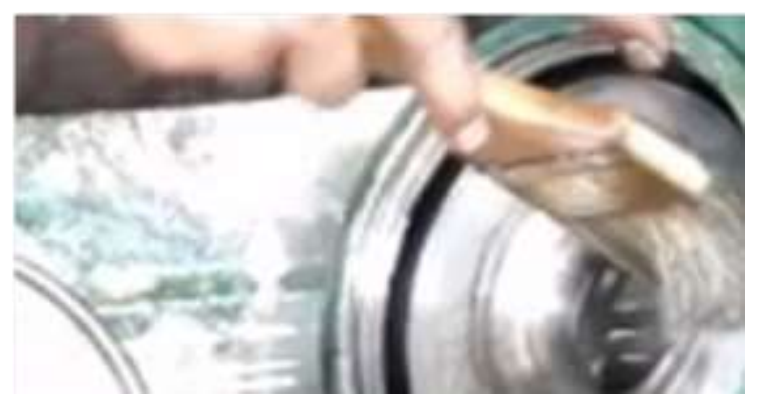

\section{Gambar 7. Pembersihan Cover/Penutup Tube}

Proses membersihkan bagian dalam FWC (Gambar 8) dengan menyiram body FWC menggunakan air tawar yang bersih tanpa menggunakan detergen, hal ini untuk menghindari detergen masuk ke dalam sistem pendinginan mesin. Untuk bersihkan body dengan menggosok menggunakan sikat nilon hingga bersih lalu bilas dengan air tawar. Setelah dibilas dengan air tawar selanjutnya di keringkan menggunakan lap majun yang bersih.

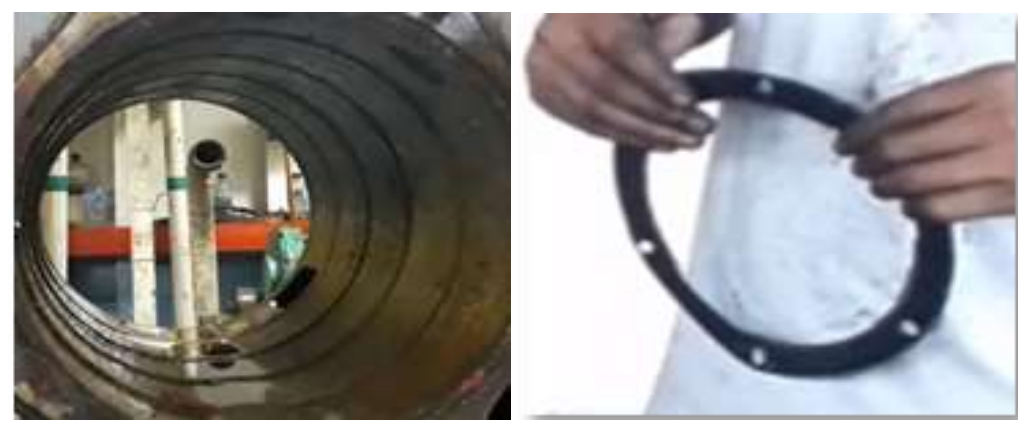

Gambar 8. Bagian dalam FWC dan membersihkan paking 
e. Pemasangan kembali FWC

Pasang tube yang sudah di bersihkan secara perlahan-lahan ke dalam body FWC, pada saat pemasangan yang harus diperhatikan adalah ketepatan pemasangan tube FWC hingga posisi kedudukan tube benar-benar tepat pada dudukannya untuk selanjutnya persiapan memasang paking (

Gambar 9.a).

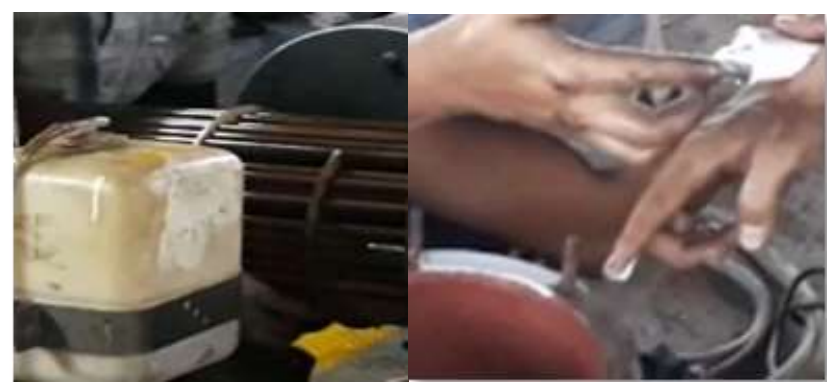

(a)

(b)

Gambar 9. (a) Pemasangan tube FWC (b) memberikan pasta perapat pada paking

Untuk mencegah kebocoran pendingin, maka saat melakukan pemasangan cover FWC, paking harus dalam kondisi yang baik, untuk menjamin tidak adanya kebocoran maka pada kedua permukaan sisi perapat di olesi dengan pasta perapat (

Gambar 9.b) hingga merata pada seluruh permukaan ke dua sisinya. Kemudian pasang cover/penutup FWC pada dua sisi tube. Pada saat pemasangan cover/penutup FWC harus teliti dan hati-hati jangan sampai salah penempatan ataupun terbalik.

Setelah semua di laksanakan pasang kembali baut-baut pada posisinya semula lalu di kencangkan baut menggunakan tools yang sesuai dengan ukurannya, dan dilanjutkan ke proses pengisian air pendingin. Proses pengisian air pendingin secara umum sama dengan penambahan air, hanya saja untuk pengisian air pendingin setelah proses pembersihan membutuhkan volume coolant sebanyak 19 liter.

Hati-hati dalam pekerjaan perawatan shell and tube karena seperti yang dikatakan oleh (Faisyal et al., 2017) ceroboh dalam melakukan perawatan dapat mengakibatkan kerusakan seperti phisical damage karena benturan, korosi karena penggunaan media pendingin yang tidak tepat dan tidak melaksanakan perawatan sesuai petunjuk manual. Waktu perawatan heat exchanger mesin penggerak generator ditampilkan pada Tabel 3.

Tabel 3. Waku dan Jumlah Pekerja

\begin{tabular}{lcc}
\multicolumn{1}{c}{ Pekerjaan } & $\begin{array}{c}\text { Waktu } \\
\text { (menit) }\end{array}$ & $\begin{array}{c}\text { Jumlah Pekerja } \\
\text { (orang) }\end{array}$ \\
\hline Penambahan coolant & 1 & 1 \\
Memeriksa temperatur air tawar & 5 & 1 \\
Membuat larutan coolant sebagai media pendingin & 5 & 1 \\
Penambahan air pendingin & & 1 \\
Cleaning shell and tube FWC & 5 & 2 \\
Drain coolant (buang air pendingin) & 15 & 2 \\
lepas tube dari shell-nya & 30 & 2 \\
Cleaning shell dan tube & 15 & 2 \\
Pemasangan kembali tube ke shell-nya & 10 & \\
Pengisian FWC dengan coolant & & \\
\hline
\end{tabular}

Tindakan perawatan FWC di atas kapal navigasi dalam kondisi normal dapat dilakukan oleh dua orang pekerja (ABK mesin), dan pekerjaan yang membutuhkan waktu paling banyak dalam adalah cleaning shell and tube FWC yaitu 75 menit. 
Sebelum dilakukan pembersihan FWC, temperatur coolant mencapai $81-85^{\circ} \mathrm{C}$. Hasil dari tindakan perawatan yang telah dilaksanakan adalah kondisi temperatur coolant yang kembali normal $75-80^{\circ} \mathrm{C}$, temperatur ini sesuai dengan artikel yang ditulis oleh (Wang, Liu, \& Zhou, 2018) dan (Zhang et al., 2017).

\section{Kesimpulan}

Kesimpulan penelitian ini perawatan FWC pada kapal navigasi sudah berjalan dengan baik hal ini di tunjukan dengan perawatan yang rutin dan terjadwal. Perawatan yang dilakukan pada FWC adalah penambahan coolant dan cleaning shell and tube FWC. Dalam pelaksanaan operasional mesin tidak pernah mesin mengalami overheat akibat kelalaian perawatan FWC. Pelaksanaan perawatan sudah sesuai instruksi kerja sehingga dalam pelaksanaannya tidak mengalami gangguan yang signifikan, hasil perawatan sesuai dengan yang diharapkan, temperatur coolant setelah dibersihkan kembali sesuai dengan standar pembuat mesin dan tidak ada kecerobohan dalam pekerjaan yang mengakibatkan tidak berhasilnya perawatan FWC ataupun kecelakaan baik pada benda kerja ataupun teknisi yang bekerja.

\section{Daftar Pustaka}

Abrori, M. Z. L., Priharanto, Y. E., Prasetyo, D., \& Muhfizar. (2018). Preliminary Hazard Analysis dan Fault Tree Analysis untuk Identifikasi Penyebab Kegagalan Sistem Pelumas Mesin Induk Kapal Penangkap Ikan. Jurnal Airaha, VII (2), 77-87. Retrieved from http://jurnalairaha.org/index.php/airaha/article/download/94/78.

Aisyah, S. N. (2016). Hubungan Kepatuhan Instruksi Kerja dengan Perilaku Aman pada Karyawan bagian Mekanik PT. Indo Acidatama Tbk Kemiri Kebakkramat Karanganyar. Tesis. Universitas Muhammadiyah Surakarta.

Amalina, M. N., \& Kristianto, T. A. (2017). Desain Interior Kapal Navigasi S-126 Untuk Meningkatkan Kualitas Keamanan, Kenyamanan, dan Memenuhi Standard Kode Kapal Yang Berlaku. Jurnal Sains Dan Seni ITS, 6 (2), G389-G394.

Basri, K. A. H., \& Aryawan, W. D. (2019). Desain Konsep Kapal Perang Serbu Catamaran Tank Boat Dengan Sistem Penggerak Utama Turbojet Sebagai Kekuatan Pengamanan Wilayah Maritim Indonesia. Jurnal Teknik ITS, 7 (2), 173-179.

Caterpillar Inc. (2007). Maintenance Interval. In 3408C, 3412, 3412C and 3412D High Performance Marine Engines. Retrieved from safety.cat.com. Diakses pada 1 Oktober 2019.

Caterpillar Inc. (2010). Maintenance Interval. In Operation and Maintenance Manual. Retrieved from safety.cat.com. Diakses pada 1 Oktober 2019.

Djunaidi, M., \& Mila Faila Sufa. (2007). Usulan Interval Perawatan Komponen Kritis Pada Mesin Pencetak Botol ( Mould Gear ) berdasarkan Kriteria Minimasi Downtime. Jurnal Teknik Gelagar, 18 (1), 33-41.

Faisyal, F., Aviva, D., \& Mustafa, M. (2017). Analisa Penyebab Kerusakan Komponen Heat Exchanger pada Sistem Pendingin Engine Marine 3306 Caterpillar. Prosiding SENIATI, 3 (2), 21-24.

Julianto, T. (2019). Pemanfaatan Perbedaan Temperatur pada Main Engine Cooling System sebagai Energi Alternatif untuk Pembangkit Listrik di Kapal. Jurnal Teknik ITS, 5 (2), 0-4. https://doi.org/10.12962/j23373539.v5i2.19434.

Priharanto, Y. E., Latif, M. Z., \& HS, R. S. (2017). Penilaian Risiko pada Mesin Pendingin di Kapal Penangkap Ikan Dengan Pendekatan FMEA. Jurnal Airaha, 6 (1), 24-32.

Pujo, E., \& Akhmad, A. (2010). Pengembangan Sistem Pakar untuk Diagnosis Kerusakan Mesin Diesel. Jurnal Ilmiah Universitas Hang Tuah, 1, 16.

Saputra, R. S. H., Priharanto, Y. E., \& Latif A, M. Z. (2018). Failure Mode and Effect Analysis (Fmea ) Applied for Risk Assessment of Fuel Oil System on Diesel Engine of Fishing Vessel. ARPN Journal of Engineering and Applied Science, 13 (21), 8414-8420. 
Soebiyakto, G. (2012). Pengaruh Penggunaan Water Coolant terhadap Performance Mesin Diesel. Widya Teknika, 20 (1).

Wang, S., Liu, C., \& Zhou, Y. (2018). Study on Waste Heat Utilization Device of High-Temperature Freshwater in the Modern Marine Diesel Engine. IOP Conference Series: Earth and Environmental Science, 111 (1), 12009. IOP Publishing.

Zhang, F., Xu, S., Feng, D., Chen, S., Du, R., Su, C., \& Shen, B. (2017). A Low Temperature MultiEffect Desalination System Powered by The Cooling Water of A Diesel Engine. Desalination, 404, 112-120. 